\title{
Reaction time after head injury: fatigue, divided and focused attention, and consistency of performance
}

\author{
D T STUSS, * L L STETHEM, H HUGENhOLTZ, T PICTON, J PIVIK, M T RICHARD
}

From the Schools of Medicine (Neurology), Surgery (Neurosurgery) and Psychology, University of Ottawa; Human Neurosciences Research Unit, University of Ottawa; Department of Psychology, Ottawa General Hospital, Canada

SUMMARY Three groups of patients who had suffered head injury were compared with matched control subjects on reaction time (RT) tasks. Group I consisted of outpatients previously hospitalised for head injury of wide ranging degrees of severity, assessed at varying intervals after injury. Group II was composed of non-hospitalised mildly concussed patients. Group III was made up of head injured patients of varying degrees of severity assessed 7-10 months after initial hospitalisation for their injury. The reaction time tests were graded in difficulty, from a simple RT response to a complex choice RT test. In addition, subjects were compared in their ability to ignore redundant information during one of the choice RT tests. The findings indicate that traumatic brain injury causes slower information processing, deficits in divided attention, an impairment of focused attention, and inconsistency of performance.

Reaction time (RT) tests have consistently revealed slowness of information processing, a deficit in divided attention after head injury.' In this study, we addressed four specific issues concerning the effects of head injury on reaction time.

The question of fatigue was examined by using the same simple RT test at the beginning and end of experimental sessions to see if head injured patients and normal control subjects changed their performance differently across the session.

A second question addressed the nature of the attentional deficit. While "There can be no controversy ... about the presence of DADs [divided attention deficit] in head injury", ${ }^{2}$ there has been less success in identifying a specific impairment in focused attention. ${ }^{3-6}$ Focused attention is tested by evaluating the ability to ignore distracting stimuli. A selective involvement of frontal lobe areas has been suggested in head injury ${ }^{7-10}$ and deficits in focused attention using

*Present address: the Rotman Research Institute of Baycrest Centre, and University of Toronto, Canada.

Address for reprint requests: Dr D T Stuss, Rotman Research Institute of Baycrest Centre, 3560 Bathurst St, Toronto, Ontario M6A 2EI, Canada

Received 10 November 1987 and in final revised form 18 November 1988.

Accepted 1 December 1988 the Stroop 1 test have been described after focal frontak lobe damage. ${ }^{12}$ Frontal lobe dysfunctions include an inability to use knowledge to guide behaviour and difficulty in ignoring extraneous information..$^{13-14}$ In this study we examined head injured patients' ability to ignore redundant information in a RT test.

A third issue was the consistency of performance. Consistency may be reflected in intraindividual variability in reaction time. Increased variability in performance after head injury has been observed, ' but this requires replication. This issue was also addressed by retesting patients at different intervals using the same paradigm.

Finally, variations among different groups of patients, including severity indices, may affect results. Differences in post-traumatic amnesia, for example, appear to correlate with eventual outcome. ${ }^{15} \mathrm{We}$ studied the possible effect of patient differences on our RT tasks by assessing three different groups of head injured patients, all compared with matched control subjects: (1) initially hospitalised head injured patients of varying initial severity referred retrospectively for neuropsychological examination, assessed at varying intervals after head injury; (2) mildly concussed patients, never hospitalised, all assessed at defined intervals within the first three months after injury; (3) initially hospitalised head injured patients of varying initial severity, part of a prospective study, all assessed at 7-10 months post injury. Correlational analyses 
examined the relationship between severity indices and RT.

\section{Methods}

The different patient populations were evaluated in separate experiments. Control subjects were different for each study. In all three studies, the injury in the majority of patients was caused by motor vehicle accidents, with a minority occurring in falls. All were closed head injuries.

\section{Subjects: Study I}

Twenty-six outpatients, who had originally suffered a head injury requiring hospitalisation, were subsequently referred for neuropsychological assessment. All patients referred over a period of approximately 30 months and capable of completing the RT tests (absence of hemiplegia) were examined. Time from injury to assessment ranged from 2 144 months post-injury: 13 within 12 months of injury; 8 were 12 to 36 months; and 5 were more than 36 months. The severity of the head injury was characterised by coma duration, Ommaya and Gennarelli's ${ }^{16}$ clinical classification, duration of post-traumatic amnesia (PTA), Glasgow Coma Scale (GCS) at specified intervals after injury and the presence or absence of a focal or diffuse mass injury as defined by CT. Of the 26 , nine had an abnormal CT scan, nine normal, and eight did not undergo CT for clinical reasons. Six of the nine abnormal CT scans reflected a mass lesion. Table 1 outlines the major clinical characteristics of the head injury patients. Patients were matched for age $(+/-3 \mathrm{yr})$, education $(+/-2 \mathrm{yr})$ and sex with normal control subjects, none of whom had any history of neurological or psychiatric disorder. No participant was colour blind. Table 2 summarises the major demographic characteristics of the patient and control groups.

\section{Subjects: Study 2}

Criteria for inclusion in study 2 were as follows: mild concussion (defined as a head injury with loss of consciousness but without demonstrable focal neurological deficit); no intoxication at the time of injury; no hospitalisation; and no colour blindness. Twenty-two of 36 patients referred completed the experimental protocol. Fourteen other patients did not return for all test sessions. These patients did not differ

\section{Table 1 Initial indices of severity in the TBI groups}

\begin{tabular}{|c|c|c|c|c|c|}
\hline Study & Measure & $N$ & $M$ & $S D$ & Range \\
\hline \multirow[t]{2}{*}{ I } & $\underset{\text { initial }}{\text { Ommaya \& Gennarelli Index- }}$ & 26 & $3 \cdot 2$ & $1 \cdot 1$ & $1-5$ \\
\hline & $\begin{array}{l}\text { Glasgow Coma Scale (one wk) } \\
\text { Coma duration (in days) } \\
\text { Post-traumatic amnesia (in } \\
\text { days) }\end{array}$ & $\begin{array}{l}26 \\
26 \\
26\end{array}$ & $\begin{array}{r}13 \cdot 7 \\
5 \cdot 5 \\
20 \cdot 4\end{array}$ & $\begin{array}{r}2.2 \\
16 \cdot 4 \\
36.0\end{array}$ & $\begin{array}{l}7-15 \\
0-75 \\
0-135\end{array}$ \\
\hline II & Ommaya \& Gennarelli Index- & 22 & 1.32 & 0.5 & $1-2$ \\
\hline \multirow[t]{2}{*}{ III } & Ommaya \& Gennarelli Index- & 22 & $3 \cdot 7$ & $1 \cdot 2$ & $1-5$ \\
\hline & $\begin{array}{l}\text { Glasgow Coma Scale (one wk) } \\
\text { Coma duration (in days) } \\
\text { Post-traumatic amnesia (in } \\
\text { days) }\end{array}$ & $\begin{array}{l}22 \\
22 \\
22\end{array}$ & $\begin{array}{l}11 \cdot 2 \\
13.0 \\
31 \cdot 4\end{array}$ & $\begin{array}{r}3.5 \\
3.2 \\
47.5\end{array}$ & $\begin{array}{l}5-15 \\
6-24 \\
1-178\end{array}$ \\
\hline
\end{tabular}

from the twenty-two on any of the major variables. ${ }^{17}$ Each of these patients was evaluated neurologically within an hour of injury. Seven of the 22 reported a previous concussion. Symptoms reported included headache, ${ }^{16}$ dizziness, ${ }^{13}$ and other various problems. ${ }^{21}$ Symptoms persisted on average of $13 \cdot 2$ days $(S D=15$, range $=0-89)$. These patients were off work for a mean of $8 \cdot 4$ days $(S D=10 \cdot 2$, range $=0-89)$. The Concussed Group was compared with matched control subjects as in Study 1 (see tables 1 and 2).

Subjects: Study 3

Twenty-two subjects involved in a prospective study were administered the RT tests. All subjects $(n=60)$ hospitalised for head injury over an 18 month period were followed. They were subsequently referred for a neuropsychological examination 7-10 months post-injury. Thirty-eight were not available for the following reasons: deceased $=2$; unresponsive/ still hospitalised $=5$; refused to participate $=12$; age $(>65)=7$; psychiatric problems $=1$; inaccessible or transferred to other hospitals $=3$; complete data not available $=8$. Tables 1 and 2 describe the remaining patients and their controls.

\section{Apparatus}

The stimuli for the Reaction Time Battery were controlled by a personal computer. They were displayed on a $35 \mathrm{~cm}$ colour monitor situated $1.5 \mathrm{~m}$ from the subject. The stimuli were white or coloured, depending on the test, and the background was dark grey. The testing room was in darkness. The approximate size for each stimulus was $5 \times 5 \mathrm{~cm}$. The mean interstimulus interval was $5 \mathrm{~s}$ with a range of $2 \mathrm{~s}$. Subjects used one button in the preferred hand for the Simple Reaction Time (SRT) tests and one button in each hand for the Multiple Choice Reaction Time (MCRT) tests.

\section{Reaction time tests}

(1) Simple Reaction Time Test (SRT): The subject was asked to press a button in his/her preferred hand, as quickly as possible, in response to the presentation of a stimulus. The stimulus was randomly selected from among four designs (a circle, square, triangle or cross) and was constant throughout the test. Five practice trials were followed by 50 test trials. The dependent measure for this test was the mean reaction time in milliseconds.

(2) Multiple Choice Reaction Time Tests (MCRT): Three MCRT tests-Easy, Complex, Redundant-were administered. The stimuli for each were considered as either "Target" or "Nontarget". In all conditions, stimuli were randomly presented. The Target stimulus had a $25 \%$ probability of presentation and was randomly selected prior to test onset. The subject pressed the button in the preferred hand in response to a Target and the button in the other hand in response to a Nontarget. In each case 10 practice trials were followed by 100 test trials. For each MCRT test, only the Target correct response times were analysed for sake of simplicity.

Easy Multiple Choice Reaction Time Test (MCRT EASY): One of the four white geometric shapes (a circle, square, triangle and cross) was randomly selected as the Target, the remaining three being Nontargets.

Complex Multiple Choice Reaction Time Test (MCRT COM$P L E X)$ : Stimuli had three different components (shape, 
Table 2 Description of the three TBI and their matched Control Groups

\begin{tabular}{|c|c|c|c|c|c|c|c|c|c|}
\hline \multirow[b]{2}{*}{ Study } & \multirow[b]{2}{*}{ Variable } & \multicolumn{4}{|c|}{ TBI patients } & \multicolumn{4}{|c|}{ Control subjects } \\
\hline & & $N$ & $M$ & $S D$ & Range & $N$ & $M$ & $S D$ & Range \\
\hline I & $\begin{array}{l}\text { Sex (male) } \\
\text { Age } \\
\text { Edemale) } \\
\text { Education }\end{array}$ & $\begin{array}{r}20 \\
6 \\
26 \\
26\end{array}$ & $\begin{array}{l}30 \cdot 9 \\
12 \cdot 0\end{array}$ & $\begin{array}{r}11.9 \\
2.7\end{array}$ & $\begin{array}{r}17-57 \\
7-20\end{array}$ & $\begin{array}{r}20 \\
6 \\
26 \\
26\end{array}$ & $\begin{array}{l}29 \cdot 7 \\
13.2\end{array}$ & $\begin{array}{r}12 \cdot 4 \\
3 \cdot 0\end{array}$ & $\begin{array}{r}16-20 \\
5-20\end{array}$ \\
\hline II & $\begin{array}{l}\text { Sex (male) } \\
\text { Age } \\
\text { (female) } \\
\text { Education }\end{array}$ & $\begin{array}{r}15 \\
7 \\
22 \\
22\end{array}$ & $\begin{array}{l}29 \cdot 5 \\
14 \cdot 4\end{array}$ & $\begin{array}{r}12 \cdot 6 \\
3 \cdot 2\end{array}$ & $\begin{array}{r}16-57 \\
9-20\end{array}$ & $\begin{array}{l}22 \\
22\end{array}$ & $\begin{array}{l}27 \cdot 7 \\
15 \cdot 5\end{array}$ & $\begin{array}{r}11 \cdot 6 \\
2.6\end{array}$ & $\begin{array}{l}16-54 \\
11-20\end{array}$ \\
\hline III & $\begin{array}{l}\text { Sex (male) } \\
\quad \text { (female) } \\
\text { Age } \\
\text { Education }\end{array}$ & $\begin{array}{r}14 \\
8 \\
22 \\
22\end{array}$ & $\begin{array}{l}26 \cdot 6 \\
11 \cdot 8\end{array}$ & $\begin{array}{r}11 \cdot 7 \\
1 \cdot 7\end{array}$ & $\begin{array}{r}15-61 \\
9-15\end{array}$ & $\begin{array}{l}22 \\
22\end{array}$ & $\begin{array}{l}27 \cdot 0 \\
12 \cdot 5\end{array}$ & $\begin{array}{r}12 \cdot 5 \\
1 \cdot 6\end{array}$ & $\begin{array}{r}16-63 \\
9-17\end{array}$ \\
\hline
\end{tabular}

colour, and line orientation within the shape), each of which could appear in one of four possible states. The shape could be a circle, square, triangle or cross. The colour could be red, blue, green or yellow. The line orientation could be vertical, horizontal, backward slanting ( ) or forward slanting (/). The Target possessed a randomly selected combination of these states, that is, a blue circle filled with vertical lines. Nontargets were stimuli that did not possess all three of the states belonging to the Target. For example, relative to the aforementioned Target, the following would be Nontargets: a red circle with vertical lines; a blue square with horizontal lines; a yellow triangle with backward slanting lines. The probability of one or more specific target state (such as blue, circle or vertical lines) being in a Nontarget was $50 \%$.

Redundant Multiple Choice Reaction Time Test (MCRT REDUNDANT): The stimuli in this condition were characterised by three components as in the MCRT COMPLEX condition. However, no state specific to the Target could ever appear in a Nontarget. For example, if the Target was a red circle with vertical lines, no Nontarget would be red, be a circle or possess vertical lines. Subjects were informed of these constraints but were not instructed to focus on any one state. Hence the stimuli appeared to be as complex as in the MCRT COMPLEX but most of the information provided was redundant. If the subject focused on only one stimulus state at a time, the test reverted to the same level of difficulty as the MCRT EASY.

Procedure In study 1 subjects were tested twice, intersession duration being one week. In study 2 , subjects were tested five times: (1) within 3 days of injury; (2) 7-10 days after injury; (3) 14-17 days; (4) 28-31 days; (5) 88-90 days. In study three, subjects were tested once, 7-10 months postinjury. Each testing session lasted 90 minutes; the time of day was kept constant within subjects. The reaction time tests were presented in the order described with brief rest periods between tests. The SRT task was repeated following completion of the other RT tests, providing two measures of SRT: SRT1, SRT2. The instructions for the reaction time tests emphasised both speed and accuracy. Care was taken to give identical instructions for each visit.

Analyses Prior to the statistical analysis of the reaction time data, extreme scores (outliers), defined as those test trial times exceeding the critical value for rejection of $p<0.01$, were removed from the sample. ${ }^{18}$ Number of outliers and number of errors for each group were compared. Log transformation was not used, as indices of variability (for example, standard deviation) were a specific research question. Individual mean scores were used for all analyses. Correlations between mean and median RT measures were completed on a random sample of 10 patients from study I for both visits. Correlations for all dependent RT measures were highly significant $[\mathrm{p}<0.001]$ and exceeded 0.97 .

Split-plot ANOVAs were performed on the test results fơ each study separately. Clinical diagnosis was the groupin factor with test as the within-subject factor. Because consis tency of performance was a research question, we decided ti analyse results within visits in order not to average oy variability. Results were considered significant if they exceeded $p<0.01$ on the omnibus $\mathrm{F}$ (in two group comparc. $\overrightarrow{0}$ isons) or $p<0.05$ on the omnibus $\mathrm{F}$ and $p<0.05$ on to conservative Geisser-Greenhouse $F$ ratio. Post hoc comparisons were performed using the Newman-Keuls Method. Unless otherwise stated, analyses described pertain to the first visit for all three studies.

For all patient groups, Pearson Product-Moment correlations analysed the degree of association between RT results and the severity indices. Time since injury was correlated with RT for study I. To provide an index of reliability, MCRT test results from Study I were correlated between the first and second visits, and between the first and second halves on the first visit.

\section{Results}

\section{Errors and outliers}

There was no statistically significant group effect for the number of errors made or outliers removed for any of the three studies for any visit. Range of errors on the MCRT tests was 0.7 to $6 \cdot 1$, the most errors occurring on the Complex MCRT test.

\section{Reliability measures}

Reliability results for the different dependent measures ranged from $\mathrm{r}=0.70-0.98, \mathrm{p}<0.001$, for the first 
versus the second half of the first visit. The first versus second visit correlation results were equally strong with a range of $r=0.60-0.94, p<0.001$.

\section{Simple Reaction Time Tests}

Head injured patients were consistently slower than control subjects on the Simple RT tests (see table 3). However, this difference reached significance only for study $3[\mathrm{~F}(1,42)=8.9, \mathrm{p}<0.01]$. Both patients and control subjects were slower on SRT2 compared with SRT1. A significant test effect, however, was also observed only for study $3[\mathrm{~F}(1,42)=10 \cdot 2, \mathrm{p}<0.001]$. For the second visit (studies 1 and 2), both studies revealed a significant test effect (SRT2 slower than SRT1).

\section{Multiple Choice Reaction Time Target responses}

There were significant test differences for all three studies, and significant group differences for studies 1 and 2 (see table 4 ). In study 3 the group difference almost reached significance $[\mathrm{F}(1,42)=5 \cdot 3, \mathrm{p}=0 \cdot 03]$. For all three studies, the patients were slower than the control subjects for all three choice RT tests. In addition, for both TBI and control subjects, reaction times were slower for the Complex choice than for either both Redundant or Easy tasks.

Studies 1 and 2 for the second visit both revealed significant group by test interactions (see table 4). In study 1 , as in the first visit, the head injured patients were slower than the control subjects for all choice tests. There were significant differences within each group when the tests were compared. Within the control group, as expected, the Complex task results were significantly slower than the Easy and Redundant MCRT measures. For the patients, in addition to the Complex RT being significantly slower than the

Table 3 Means, Standard Deviations for all measures for all three studies for the first visit

\begin{tabular}{|c|c|c|c|c|c|}
\hline \multirow{2}{*}{\multicolumn{2}{|c|}{ Study Measure }} & \multicolumn{2}{|c|}{ TBI patients } & \multicolumn{2}{|c|}{$\begin{array}{l}\text { Control } \\
\text { subjects }\end{array}$} \\
\hline & & \multirow{2}{*}{$\begin{array}{l}\text { Mean } \\
333.9 \\
350 \cdot 5 \\
559 \cdot 8 \\
672.1 \\
583.8\end{array}$} & \multirow{2}{*}{$\begin{array}{l}S D \\
292 \cdot 3 \\
205 \cdot 5 \\
261 \cdot 4 \\
292 \cdot 3 \\
281 \cdot 1\end{array}$} & \multirow{2}{*}{$\begin{array}{c}\text { Mean } \\
243 \cdot 1 \\
266 \cdot 5 \\
433 \cdot 3 \\
512.6 \\
439.6\end{array}$} & \multirow{2}{*}{$\begin{array}{l}S D \\
67 \cdot 1 \\
78 \cdot 7 \\
53 \cdot 9 \\
78 \cdot 3 \\
67 \cdot 7\end{array}$} \\
\hline I & $\begin{array}{l}\text { SRT } 1 \\
\text { SRT } 2 \\
\text { MCRT Easy } \\
\text { MCRT Comp } \\
\text { MCRT Red. }\end{array}$ & & & & \\
\hline II & $\begin{array}{l}\text { SRT } 1 \\
\text { SRT } 2 \\
\text { MCRT Easy } \\
\text { MCRT Comp } \\
\text { MCRT Red. }\end{array}$ & $\begin{array}{l}282 \cdot 8 \\
300 \cdot 0 \\
516 \cdot 1 \\
617 \cdot 4 \\
541 \cdot 5\end{array}$ & $\begin{array}{r}108 \cdot 2 \\
66 \cdot 5 \\
142 \cdot 5 \\
196 \cdot 1 \\
171 \cdot 7\end{array}$ & $\begin{array}{l}237 \cdot 4 \\
257 \cdot 6 \\
427 \cdot 5 \\
513 \cdot 5 \\
431 \cdot 9\end{array}$ & $\begin{array}{l}44 \cdot 0 \\
48 \cdot 3 \\
49 \cdot 2 \\
68 \cdot 0 \\
59 \cdot 8\end{array}$ \\
\hline III & $\begin{array}{l}\text { SRT } 1 \\
\text { SRT } 2 \\
\text { MCRT Easy } \\
\text { MCRT Comp } \\
\text { MCRT Red. }\end{array}$ & $\begin{array}{l}286 \cdot 3 \\
322 \cdot 3 \\
554 \cdot 7 \\
633 \cdot 7 \\
571 \cdot 8\end{array}$ & $\begin{array}{r}88.6 \\
110 \cdot 6 \\
198 \cdot 9 \\
259 \cdot 3 \\
226.6\end{array}$ & $\begin{array}{l}228 \cdot 1 \\
247 \cdot 0 \\
442 \cdot 0 \\
523 \cdot 3 \\
452 \cdot 3\end{array}$ & $\begin{array}{r}20 \cdot 8 \\
68 \cdot 7 \\
72 \cdot 1 \\
152 \cdot 4 \\
79 \cdot 5\end{array}$ \\
\hline
\end{tabular}

Table 4 Significant differences for the Choice RT tests for all three studies

\begin{tabular}{lllrl}
\hline & Condition & D.F. & $F$ & Sig. \\
\hline First visit study & & & \\
I & Group & 1,50 & 7.0 & 0.01 \\
& Test & 2,100 & 29.6 & $<0.001$ \\
II & Group & 1,42 & 7.6 & 0.009 \\
& Test & 2,84 & 43.7 & $<0.001$ \\
III & Test & 2,84 & 11.2 & $<0.001$ \\
& & & & \\
Second visit study & & & \\
I $\quad$ Group $\chi$ Test & 2,100 & 4.3 & 0.016 \\
II & Group $\chi$ Test & 2,84 & 4.8 & 0.01 \\
\hline
\end{tabular}

Easy and Redundant RT tasks, the Redundant reaction time was also significantly slower than the Easy RT test (fig 1). The study 2 interaction stemmed from the control group reacting more slowly on the Easy than on the Redundant task on the second visit.

\section{Consistency of performance}

Consistency of performance was analysed by comparing the individual standard deviations of the patients and control subjects. For this analysis subjects from all three studies were grouped together on their first visits' results. There was a significant group effect for the SRT analysis $[\mathrm{F}(1,135)=7.4, \mathrm{p}<0.01]$ and the MCRT results $[F(1,135)=16 \cdot 6, p<0.01]$. For all comparisons, the head injured patient showed a significantly greater variability in performance as assessed by his/her standard deviations.

Consistency of performance may be evident in other ways. For example, in the SRT analysis of study 1 , in comparison with the control group, patients showed a smaller fatigue effect for the first visit but a greater fatigue effect for the second visit. In this same study, the Redundancy effect was observed only on the second visit. In study 2 concussed patients, while not statistically significant, demonstrated variability of the Redundancy effect over the five visits. For certain visits, the Redundant-Easy RT scores are equivalent; for other visits, the Redundancy effect is more prominent (see fig 2).

\section{Correlational analyses}

The possible influence of patient characteristics was evaluated by correlational analyses. For studies 1 and 2 , no correlations exceeded the critical value of $\mathrm{p}<0.01$. Two correlations were approximate in study 1. For the second visit only, the Glasgow Coma Scale at 1 week correlated significantly with the difference between the Easy and Redundant RT measures: $r=-0.43, p=0.016$. The more severe the head injury the greater the redundancy effect. In addition, time since injury correlated with the standard deviation of the Complex MCRT test: $r=-0.42$, 


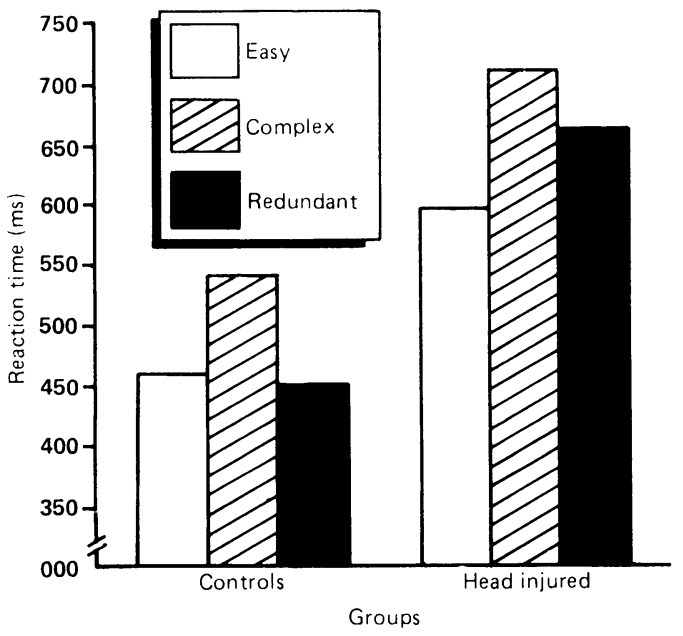

Fig 1 Study l, Second Visit: Reaction time for all three Multiple Choice Reaction Time Conditions for both the Control and Head injured groups. This demonstrates the redundancy effect for the Head Injured patients.

$p=0 \cdot 018$. The shorter the time since the TBI, the greater the variability.

In study 3 , in which patients of varying levels of initial severity of head injury were evaluated within a defined interval after the injury, all $\mathrm{RT}$ results correlated with the following measures at $p<0.01$ : GCS at 1 week (range -0.57 to -0.71 ); PTA (range 0.79 to 0.88 ). GCS at varying intervals after injury and the Ommaya and Gennarelli index also were highly significant, but not with all dependent measures.

\section{Discussion}

Fatigue

The Simple RT tests re-evaluated the effect of TBI on visuo-motor response. The repetition of the SRT task assessed the effects of fatigue over one hour on RT visuo-motor speed.

Speed of visuo-motor responsiveness on the Simple RT tasks has a tendency to be slower after head injury. In our study, however, the effect was not consistent, and was significant only in more severe, recent injury (Study 3 ). This may explain the variability of results in previous studies. ${ }^{49}$ There was no significant fatigue effect for either group.

\section{Consistency of performance}

Consistency of performance may consist of several components.' One is individual variability, measured by the standard deviation. The head injured patients had significantly greater variability in this regard. A second is consistency of performance over longer periods of time, reflected in the differences in results over repeated assessments. Our results indicate that variability, both within a test and across assessments, is greater in the brain injured patients than in the control subjects.

Disturbance in consistency is an overlooked impair ment after traumatic brain injury. Even when patients appear to do a task reasonably well, their ability to maintain this level of performance over time appearso to be compromised. In this regard, head injures patients as a group may be considered to suffeto impairment in sustained attention. Repeated evalua tions may be essential to reveal the true nature of the deficit.
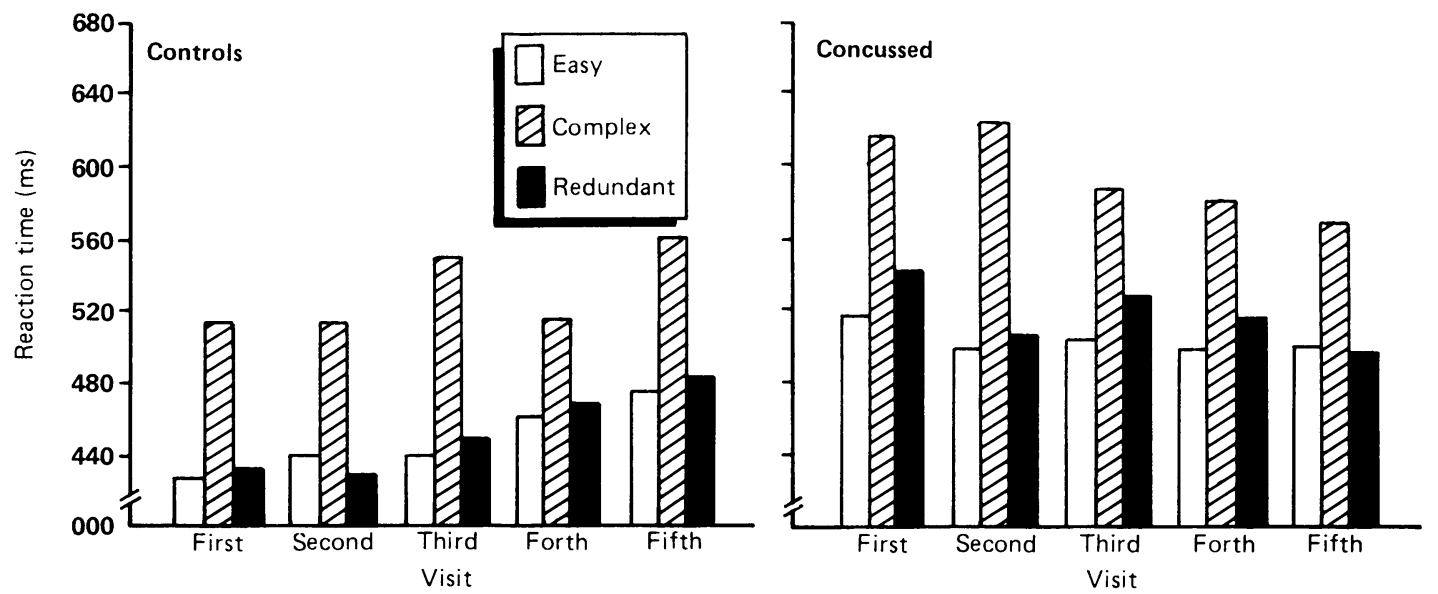

Fig 2 Multiple Choice RT results for all three tests across five visits for both the Control and Concussed subjects. 


\section{Attention deficits}

The complex tasks confirm that head injured patients have a divided attention deficit, defined as slowness in consciously controlled information processing, an inability to process multiple bits of information rapidly and easily. Our results with the MCRT tasks replicate previous findings, ${ }^{2021}$ and confirm that tasks of divided attention are sensitive to the effects of injury, even in mildly concussed or apparently recovered patients. ${ }^{1722}$

The attentional deficit after head injury consists of more than just impaired divided attention. The redundancy task had been designed to measure the possibility of a focused attention deficit, defined as the inability to suppress an automatic response when a conflicting response is demanded, or as the unnecessary processing of redundant information. The patients appeared to be less able than the control subjects to ignore redundant information. This deficit, however, was somewhat elusive. It was significant only for the hospitalised patients (study 1) on their second visit. The concussed patients (study 2 ) demonstrated considerable variability, but an analysis of their means (see Figure 2) revealed a tendency for impaired performance on the Redundant RT test which was variable over the five visits.

We propose that the attentional deficit in head injured patients is not a simple one. There is little doubt about the presence of a divided attention deficit. There also appear to be superimposed problems in focused and sustained (consistent) attention. The interactive nature of these latter two deficits make them elusive, and repeated evaluations appear necessary to elicit them. We propose that the characteristics of our tests and procedure have revealed that head injured patients as a group can rise to meet the demands of a focused attention task but are inconsistent in maintaining an optimal level of performance. Patients can temporarily improve their attentional focus by inhibiting redundant information, as revealed by the first visit results. This "top-down", focused attention, ${ }^{23}$ however, is completed at a cost and apparently cannot be maintained by all. The sustained, or more correctly repeated, demands of the task, eventually erodes the patient's ability to maintain consistent performance. From a practical viewpoint, this finding may reflect the inconsistent work performance and the problems in maintaining attention long enough to learn and use new techniques effectively that is commonly described by head injured patients. Awareness of dysfunction in consistency of effort, even in mildly concussed patients, has important treatment and management ramifications.

\section{Correlational analyses}

The lack of correlation of RT performance with other indices of severity of the head injury was somewhat surprising. RT measures have always been sensitive to the effect of head injury. Considering past studies correlating such indices as duration of PTA with outcome, significant correlations were expected but were observed only in study 3 .

The characteristics of patients in study 3 may explain these findings. These patients were more severely injured as a group than patients in study 2 . Severity of insult may be relevant. Secondly these subjects were assessed at a relatively defined time after insult. Subjects in study 1 were of an equivalent severity to those in study 3 , but the differences in time since injury in study 1 may have minimised correlations with severity. This hypothesis is at least partially supported by the fact that time since injury in study 1 was correlated at $p=0.018$ with the Complex MCRT variability results; the shorter the time since injury, the greater the variability. A third possibility is the fact that study 3 was completed prospectively. The evaluation of severity indices in study 3 was likely to be more precise than in the retrospective study.

\section{Conclusion}

Head injury does result in deficits in attention and speed of information processing. Our results suggest that the deficits can be divided into several factors. There is overall a generalised slowing in visuo-motor responsiveness, which frequently does not reach the level of significant difference. There is a divided attention deficit. In addition, however, traumatic brain injury may result in impairment in focused attention and consistency of performance, observed only with repeated assessments using a focused attention task. This is a group effect and may not be necessarily revealed in individual subjects.

We acknowledge the need for further replication of these observations, but we believe that we are justified in proposing that inconsistency and impaired focused attention are important deficits following head injury for several reasons. First, the use of different groups has provided some index of replicability. Second, our data are sufficiently strong at least to indicate the need for future research with repeated focused attention tasks. The amount of redundant information to be ignored may be a relevant variable. Third, the findings are compatible with the neuropathology of traumatic brain damage. Our final argument is based on clinical observation. Awareness that inconsistency in performance and impairment in focused attention may be prominent deficits after head injury should radiate into the understanding, management, and treatment of patients.

Funding for this research was granted by the Medical 
Research Council of Canada, the Physicians Services Incorporated of Ontario and the Ontario Mental Health Foundation. M Lecompte typed the manuscript. Computer programming and hardware construction were completed by E Leech and G Hamel. C L Della Malva, C Poirier and C Gow assisted in subject examination. The ideas for the reaction time studies were discussed with $\mathrm{Dr} \mathbf{M}$ Alexander. Selected portions of the data have been previously presented at the INS Annual Meeting, January, 1988, New Orleans.

\section{References}

I Van Zomeren AH, Brouwer WH. Head injury and concepts of attention. In: Levin HS, Grafman J, Eisenberg HM, eds. Neurobehavioral Recovery from Head Injury. New York: Oxford University Press, 1987:398-415.

2 Gronwall D. Advances in the assessment of attention and information processing after head injury. In: Levin HS, Grafman J, Eisenberg HM, eds. Neurobehavioral Recovery from Head Injury. New York: Oxford University Press, 1987:355-71.

3 Chadwick O, Rutter M, Brown G, Shaffer D. Traub M. A prospective study of children with head injuries: II. Cognitive sequelae. Psychol Med 1981;11:49-62.

4 Dencker SJ, Lofving B. A psychometric study of identical twins discordant for closed head injury. Acta Psychiat Neurol Scand 1958;33:Suppl 122.

5 Gronwall DMA. Sampson H. The Psychological Effects of Concussion. Auckland: Auckland University Press, 1974.

6 Van Zomeren AH. Reaction Time and Attention after Closed Head Injury. Lisse: Swets \& Zeitlinger, BV, 1981.

7 Alexander MP. Traumatic brain injury. In: Benson DF, Blumer D, eds. Psychiatric Aspects of Neurologic Disease. New York: Grune \& Stratton, 1982:219-49.

8 Clifton GL, Grossman RG, Makela ME, Miner ME, Handel S, Sadhu V. Neurological course and correlated computerised tomography findings after severe closed head injury. $J$ Neurosurg 1980;52:619-24.
9 Courville CB. Pathology of the Central Nervous System. Mountain View, CA: Pacific Press, 1937.

10 Ommaya AK. Reintegrative action of the nervous system after trauma. In: Popp AJ, Bourke RS, Nelson LR, Kimelberg HK, eds. Neural Trauma. New York: Raven Press, 1979:371-8.

11 Stroop JR. Studies of interference in serial verbal reactions. J Exp Psychol 1935;18:643-62.

12 Perret E. The left frontal lobe of man and the suppression of habitual responses in verbal categorical behaviour. Neuropsychologia, 1974;12:323-30.

13 Luria AR. The working brain. An Introduction to Neuropsychology, translated by B Haigh. New York: Basic Books, 1973.

14 Stuss DT, Benson DF. The Frontal Lobes. New York: Raven Press, 1986

15 Jennett B, Teasdale G, Braakman R, Minderhoud J, Knill-Jones R. Predicting outcome in individual patients after severe head injury. Lancet 1976;i:1031-4.

16 Ommaya AK, Gennarelli TA. Cerebral concussion and traumatic unconsciousness. Correlation of experimental and clinical observations on blunt head injuries. Brain 1974;97:633-54.

17 Hugenholtz H, Stuss DT, Stethem LL, Richard MT. How long does it take to recover from a mild concussion? Neurosurgery 1988;22:853-8.

18 Grubbs FE. Procedures for detecting outlying observations in samples. Technometics 1969;11:1-21.

19 Norman B, Svahn EK. Follow-up study of severe brain injuries Acta Psychiatrica Scandinavia 1961;37:236-64.

20 Van Zomeren AH, Brouwer WH, Deelman BG. Attentional deficits: the riddles of selectivity, speed and alertness. In: Brooks $\mathrm{N}$, ed. Closed Head Injury: Psychological, Social and Family Consequences. Oxford: Oxford University Press, 1984.

21 Van Zomeren AH, Deelman BG. Long-term recovery of visua reaction time after closed head injury. $J$ Neurol Neurosurge Psychiatry 1987;41:452-7.

22 Stuss DT, Ely P, Hugenholtz HH, et al. Subtle neuropsychologica deficits in patients with good recovery after closed head injury Neurosurgery 1985;17:41-7.

23 Treisman AM, Gelade G. A feature-integration theory attention. Cogn Psychol 1980;12:97-136. 